\title{
Predictors of modern contraceptive usage among sexually active rural women in Ethiopia: A multi-level analysis
}

Setegn Muche Fenta* (10) and Shewayiref Geremew Gebremichael

\begin{abstract}
Background: Ethiopia is one of the Sub-Saharan Africa countries with the lowest modern contraceptive prevalence rate and the highest fertility rate. This study aimed to assess individual and community-level predictors of modern contraceptive use among sexually active rural women in Ethiopia.

Data and methods: A sample of 9450 sexual active rural women aged 15-49 was extracted from the 15, 683 nationally representative samples of 2016 Ethiopian Demographic and Health Survey (EDHS). Multi-level logistic regression model was considered to identify determinant factors of modern contraceptive use among sexually active rural women in Ethiopia.

Result: The prevalence of modern contraceptive use among respondents was $20 \%$ in rural Ethiopia. Injection (66.35\%) was the most common type of modern contraceptive use. In the last full model of the multilevel analysis, individual and community-level factors accounted for $86.69 \%$ of the variation in the use of modern contraceptive methods. Secondary and above-educated women $(A O R=1.39,95 \% \mathrm{Cl}: 1.06,2.81)$, having 1-4 living children ( $A O R=$ $2.70,95 \% \mathrm{Cl}: 2.07,3.53)$, rich wealth status $(\mathrm{AOR}=2.26,95 \% \mathrm{Cl}: 1.96,2.60)$, married women $(\mathrm{AOR}=17.31,95 \% \mathrm{Cl}: 10.72$, 27.94), having primary educated husband ( $A O R=1.45,95 \% \mathrm{Cl}: 1.27,1.67)$ and being working husband $(\mathrm{AOR}=2.26$, $95 \% \mathrm{Cl}: 1.96,2.60)$ were significantly positively associated with individual-level factors of the use of modern contraceptive methods. Besides, modern contraceptive use was negatively associated with Muslim women ( $A O R=$ $0.29,95 \% \mathrm{Cl}: 0.25,0.33$ ). Compared to the Tigray region, women living in the Afar, Somali, Harari, and Dire Dawa regions had lower use of modern contraceptive methods. Women who had access to mass media (AOR $=1.35$, $95 \% \mathrm{Cl}: 1.16,1.57)$ were more likely to use contraceptives than their counterparts.

Conclusion: The prevalence of modern contraceptive use among rural women has very low. Both individual and community-level factors were significant predictors of modern contraceptive use. Consequently, the government and other stakeholders need to address educational opportunities; creating awareness about modern contraception and valuable counseling would increase modern contraceptive methods utilization.
\end{abstract}

Keywords: Ethiopia, Multi-level, Modern contraceptive, Rural women

\footnotetext{
*Correspondence: setegn14@gmail.com

Department of Statistics, Faculty of Natural and Computational Sciences,

Debre Tabor University, Debre Tabor, Ethiopia
}

(C) The Author(s). 2021 Open Access This article is licensed under a Creative Commons Attribution 4.0 International License, which permits use, sharing, adaptation, distribution and reproduction in any medium or format, as long as you give appropriate credit to the original author(s) and the source, provide a link to the Creative Commons licence, and indicate if changes were made. The images or other third party material in this article are included in the article's Creative Commons licence, unless indicated otherwise in a credit line to the material. If material is not included in the article's Creative Commons licence and your intended use is not permitted by statutory regulation or exceeds the permitted use, you will need to obtain permission directly from the copyright holder. To view a copy of this licence, visit http://creativecommons.org/licenses/by/4.0/. The Creative Commons Public Domain Dedication waiver (http://creativecommons.org/publicdomain/zero/1.0/) applies to the data made available in this article, unless otherwise stated in a credit line to the data. 


\section{Background}

In mid-2019, the world population had reached 7.7 billion, adding one billion people since 2007 and two billion since 1994. In 2030, the world population estimate will be 8.5 billion; in 2050, 9.7 billion, and 10.9 billion in 2100. Over the coming decades, Sub-Saharan Africa will account for most of the growth of the world's population, while many regions will begin to experience declining numbers of the population. About two billion people might be added to the global population between 2019 and 2050, 1.05 billion (52\%) might be added in countries of sub-Saharan Africa. The result of the high fertility rate is poor health conditions in general, and inadequate availability of medical care, the risks of pregnancy are higher in Africa than anywhere else $[1,2]$.

With a current population of 112 million with a fertility rate of 4.6 children born per woman, Ethiopia leads sub-Saharan Africa; one of the highest populations in Africa [1-7]. High fertility carries the highest risk of child mortality, as it is generally difficult for Ethiopian families to provide adequate food and health care for all their children. Hence, children could be easily affected by severe malnutrition and infections. In addition, the problem of overpopulation has also been compounded by poverty, war, drought, inadequate infrastructure, and poor agricultural and industrial production $[8,9]$.

In 2019, 190 million women of reproductive age worldwide who want to avoid pregnancy do not use any contraceptive method. About 43\% of the 206 million pregnancies that occurred in the developing world in 2017 would be unintended. Over $80 \%$ of women infected with common, curable sexually transmitted infections in developing countries are not treated [10-13]. Modern contraceptives improve the rights of people to decide their children's number and gap [14]. By avoiding unintended and high-risk pregnancies and reducing the need for unsafe abortions contraceptive use reduces maternal mortality and improves women's health. Some contraceptives also enhance the health of women by reducing the risk of transmitting disease and protecting them from certain cancers and health problems $[15,16]$. The use of contraceptives has increased in many parts of the world, especially in Asia and Latin America, but in subSaharan Africa, continue to decline. The use of modern contraceptives has slightly increased worldwide, from $54 \%$ in 1990 to $57.4 \%$ in 2015 . It goes from 23.6 to 28.5\% in Africa [17].

Modern contraceptive use among Ethiopian married women has increased from $6 \%$ in 2000 to $38 \%$ in 2018 $[5,7,10]$. By 2020, the Ethiopian government should aim to increase the prevalence of contraception to $40 \%$ for 15 to 19 years-old women, and to $43 \%$ for 20 to 24 years-old women. Furthermore, the government is committed to reducing the unmet need for the two age groups to $10 \%$ overall $[5,11]$. Nevertheless, it is still a challenge to make sure consistency in reproductive health supplies and distribution to the last mile. Gains are also precarious, with $10 \%$ more women in urban settings using modern contraception than those in rural areas. There is low contraceptive uptake and demand generation among rural populations and there is inadequate training for professionals in public health. Professionals such as-nurses and midwives may not always be ready or qualified to insert or remove techniques, including implants, and insertion kits may not even are available for the services needed. Several factors can act as obstacles to accessing family planning services for women in Ethiopia, including illiteracy, early childbearing, gender-based disparities, and religious and traditional influences. Ethiopia is far from completely addressing its population's health needs [11, 12]. The country is unlikely to meet its Family Planning 2020 (FP2020) targets of adding 6.2 million new modern users of contraceptives by 2020 [12].

In Ethiopia, studies were conducted to identify predictors of modern contraceptive use among sexually active women [10-20]. Those studies were done by using an ordinary regression model. The ordinary logistic regression model was taking into account only individual-level factors by omitting the community (cluster) effect. Yet, its underlying assumption of individual observation must be independent each other limits its use in many real-world applications with hierarchical or correlated nature of data. For this reason, the result ordinary logistic regression model might be applicable in incorrect inference about parameter estimates, standard errors, tests, and confidence intervals. The variation in the determinants of modern contraceptive use might be due to heterogeneity in the enumeration area of the study. To address this, we proposed a multilevel logistic regression model for modern contraceptive use data [21, 22]. Therefore, this study aimed to address individual and community-level predictors of modern contraceptive use among sexually active rural women in Ethiopia.

\section{Methods}

\section{Study setting}

This study was conducted in Ethiopia. Ethiopia is the second-most populous country in Africa next to Nigeria. It has a unique cultural heritage with a diverse population mix of ethnicity and religion. Located in the northeastern part of Africa; also known as the Horn of Africa. It borders six countries Eritrea (North), Djibouti (East), Somalia (South East), Kenya (South and North West), South Sudan (West), and Sudan (North West and West) $[10,11]$. 


\section{Data source and design}

The data used for this study was taken from the 2016 Ethiopian Demography and Health Survey (EDHS). In the 2016 EDHS, a two-stage stratified cluster sampling technique has been employed. In the first stage, enumeration areas were selected. Enumeration area is a geographic area consisting of a convenient number of dwelling units which served as a counting unit for the census. In the second stage, 28 households per enumeration area were selected with an equal chance of systematic selection per enumeration area.

\section{Variable of the study}

\section{Outcome variable}

The outcome variable was modern contraceptive use among sexually active women. It is a categorical variable (Yes, No). The modern contraception method includes the pill, IUD, injections, the diaphragm, female or male sterilization, the male or female condom, implants, and lactation amenorrhea contraception method.

\section{Independent variables}

The independent was selected by reviews of previous literature [10-21]. The independent variables included in the study were the wealth index, educational level of the mother, educational level of husband, age of women, occupation of women, religion, age at first birth, contraceptive use, number of living children, birth in the last three years, marital status, occupation of husband, terminated pregnancy, the region they live in, and access to mass-media.

\section{Data management and analysis}

Data were extracted and decoded using SPSS software version 21 and the decoded data were analyzed using STATA version 14. Descriptive statistics such as frequencies, percentages, and bar charts were performed to describe the study participants.

The dataset was constructed by hierarchical/multilevel study design. In the hierarchical/multilevel study design, the individual observations are not considered as independent of each other. In this study, the respondents/ women are nested with Enumeration Areas (EAs). In this case, the conventional regression model is not appropriate. Having this reason, a multilevel logistic regression model was used to identify the predictors of modern contraceptive usage among sexually active rural women in Ethiopia.

In the multilevel analysis, four consecutive models were fitted [10-13]. The first is the null model (Model I), for detecting the existence of possible contextual effect which is fitted without any explanatory variable at the individual level as well as at the community level. The second model fitted by including all individual-level variables (model II). In this step, we assess the contribution of each individual-level explanatory variable, the significance of each predictor, and what changes occur in the first-level and second-level variance terms. The third model fitted by including all community-level variables (Model III). This model allows us to look at whether the community-level explanatory variables explain the between-group variation in the dependent variable.

The result of the fixed effect is reported in terms of adjusted odds ratio with $95 \% \mathrm{CI}$. All variables with $p$ values $\leq 0.05$ have been considered as statistically significant. The measures of variation (random effects) were summarized using ICC, Median Odds Ratio (MOR), and proportional change in variance (PCV). ICC is a measure of within-cluster variation, the variation between individuals within the same cluster, and it was calculated using the formula:

$$
I C C=\frac{V_{A}}{V_{A}+\pi^{2} /}=\frac{V_{A}}{V_{A}+3.29},
$$

Where; $V_{A}$ is the estimated variance in each model, which was described elsewhere [10].

The total variation attributed to individual or/and community-level factors at each model were measured by the proportional change in variance (PCV), which is calculated as:

$$
P C V=\frac{V_{A}-V_{B}}{V_{A}},
$$

Where; $V_{A}=$ variance of the first model, and $V_{B}=$ variance of the model with more terms [10]. The MOR is the median odds ratio between the individual of higher propensity and the individual of lower propensity when comparing two individuals from two different randomly chosen clusters and it measures the unexplained cluster heterogeneity, the variation between clusters by comparing two persons from two randomly chosen different clusters. It is computed using the formula: $M O R$ $=\exp \left(\sqrt{2 * V_{A} * 0.6745}\right) \approx \exp \left(0.95 \sqrt{V_{A}}\right)$, where $V_{A}$ is the cluster level variance $[10,11]$. The MOR measure is always greater than or equal to 1 . If the $M O R$ is 1 , there is no variation between clusters [12].

\section{Model fit statistics}

Deviance Information Criteria (DIC), Akaike's Information Criterion (AIC), and Bayesian's Information Criterion (BIC) is used to compare the candidate models. The model with the smallest value of the information criterion will be selected as the final model of the analysis [13]. 


\section{Result}

\section{Socio-demographic characteristics}

A total of 9450 sexually active rural women have participated in the EDHS-2016 survey. Regarding the age distribution, it was realized that about $(33.5 \%)$ of those were youth (20 to 29) years. About 43.2\% were Muslims followed by Orthodox Christian (33.9\%). The most (67.5\%) of women were married, followed by never married (23.0\%). About half (55.0\%) were poor, 29.9\% were rich, while; others were middle wealth index status (19.0\%). About the educational level, $58.6 \%$ of women and $70.0 \%$ of their husbands were not attending formal education. The majority of the women were housewives $(70.8 \%)$. The age at first birth greater than seventeen years were $(69.0 \%)$ (Table 1$)$.

\section{The prevalence of modern contraceptive in sexually active rural women}

From a total of 9450 sexually active rural women, only 1976 (20.9\%) were using a modern contraceptive method and the rest of 7474 (79.1\%) did not use any modern contraceptive method. Among 1976 modern contraceptive users, $66.35 \%$ used injections, $23.18 \%$ used implant and the remaining $10.47 \%$ of women used the pill, IUD, female sterilization, emergency contraception, standard day method, and lactation amenorrhea method (Table 1 and Fig. 1).

\section{Predictors of modern contraceptive use among sexually active rural women in Ethiopia}

The results of the multilevel logistic model both individual and community-level variables were summarized in Table 2. The model comparison result revealed that model IV is a better fit for the data as compared to other reduced models, since it has the smallest AIC and deviance statistic. In this model all individual-level and community-level factors are included, wealth index, educational level of the mother, education level of husband, age of women, occupation of women, religion, age at first birth, contraceptive use, number of living children, birth in the last three years, marital status, occupation of husbands, region, and access to mass media were factors significantly associated with modern contraceptive use (Table 2).

\section{Individual level factors}

Attending the primary educational level was 1.31 $(\mathrm{AOR}=1.31,95 \% \mathrm{CI}: 1.22,1.51)$ times more likely to use modern contraceptives compared to not attending any formal education. Similarly, respondents with secondary and above educational level were 1.39 (AOR = 1.39, 95\%CI: 1.06, 2.81) times more likely to use modern contraceptives compared to not attending any formal education. Additionally, women who had wrought in government-employed/farmer/business were $1.19(\mathrm{AOR}=1.19,95 \% \mathrm{CI}: 1.05,1.35)$ times more probable to use modern contraceptives than those who are housewives. Respondents aged 40-49 years were $0.40(\mathrm{AOR}=0.29,95 \% \mathrm{CI}: 0.56,2.81)$ times less likely to use modern contraceptives compared to 1019 years old. Respondents having one to four living children were $2.70(\mathrm{AOR}=2.70,95 \% \mathrm{CI}: 2.07,3.53)$ times more likely to use modern contraceptives compared to respondents who had no living children. Respondents who had five or more living children were $2.49(\mathrm{AOR}=2.49,95 \% \mathrm{CI}: 1.81,3.43)$ times more likely to use modern contraceptives compared to respondents who had no living children. The likelihood of being willing to use modern contraceptives among Muslim respondents was $0.29 \quad(\mathrm{AOR}=0.29,95 \% \mathrm{CI}$ : $0.25,0.33$ ) times less likely than that for Orthodox Christian respondents. Respondents in the middle wealth index status were $2.05(\mathrm{AOR}=2.05,95 \% \mathrm{CI}$ : $1.77,2.38)$ times more likely to use modern contraceptive than those respondents with poor wealth index status. Similarly, women with a rich wealth index were $2.26(\mathrm{AOR}=2.26,95 \% \mathrm{CI}: 1.96,2.60)$ times more likely to use modern contraceptives than women with a poor wealth index. Married women were $17.31(\mathrm{AOR}=17.31,95 \% \mathrm{CI}: 10.72,27.94)$ times more likely to use modern contraceptive than those never-married women. Women whose husbands attended primary education were $1.45 \quad(\mathrm{AOR}=1.45$, 95\%CI: $1.27,1.67)$ times more likely to use modern contraceptives than those who did not attend any formal education. Besides, women whose husbands had wrought with government-employed/farmer/private business were $2.02(\mathrm{AOR}=2.26,95 \% \mathrm{CI}: 1.96,2.60)$ times more probable to use modern contraceptives than those who had not worked. Women who gave birth to a child in the last three years were 0.51 (AOR $=0.51,95 \% \mathrm{CI}: 0.44,0.51$ ) times less likely to use modern contraceptives than those women not giving birth. Similarly, Women given birth to two and more children in the last three years were 0.25 (AOR $=0.25,95 \% \mathrm{CI}: 0.19,0.34)$ times less likely to use modern contraceptive than those women not given birth (Table 2).

\section{Community-level factors}

Respondents who have got access to mass-media were $1.35(\mathrm{AOR}=1.35,95 \% \mathrm{CI}: 1.16,1.57)$ times more likely to use modern contraceptive than who had not got any mass-media. Women living in Afar (AOR $=0.12$ : $95 \% \mathrm{CI}$ : $0.07,0.20$ ), Somali (AOR $=0.04$; 95\% CI: 0.02, 0.10), Harari $(\mathrm{AOR}=0.43$; 95\%CI: 0.28, 0.65), Dire Dawa $(\mathrm{AOR}=$ 0.58; 95\%CI: $0.37,0.91$ ); regional state were less likely to use modern contraceptive as compared to women living 
Table 1 Socio-demographic characteristics of sexual active rural women in Ethiopia

\begin{tabular}{|c|c|c|c|}
\hline Variables & Categories & Frequency & Percentage \\
\hline \multirow[t]{2}{*}{ Contraceptive use } & No & 7474 & 79.1 \\
\hline & Yes & 1976 & 20.9 \\
\hline \multirow[t]{2}{*}{ Ever had a terminated pregnancy } & No & 8738 & 92.5 \\
\hline & Yes & 712 & 7.5 \\
\hline \multirow[t]{2}{*}{ Women occupation } & Housewife & 6693 & 70.8 \\
\hline & Government employed /farmer/private business & 2757 & 29.2 \\
\hline \multirow[t]{3}{*}{ Religion } & Orthodox & 3203 & 33.9 \\
\hline & Muslim & 4087 & 43.2 \\
\hline & Others & 2160 & 22.9 \\
\hline \multirow[t]{4}{*}{ Age of women } & $10-19$ & 2160 & 22.9 \\
\hline & $20-29$ & 3166 & 33.5 \\
\hline & $30-39$ & 2555 & 27.0 \\
\hline & $40-49$ & 1569 & 16.6 \\
\hline \multirow[t]{3}{*}{ Education level of women } & No education & 5535 & 58.6 \\
\hline & Primary & 3067 & 32.5 \\
\hline & Secondary and plus & 848 & 9.0 \\
\hline \multirow[t]{3}{*}{ Marital status } & Never married & 2106 & 22.3 \\
\hline & Married & 6378 & 67.5 \\
\hline & Others & 966 & 10.2 \\
\hline \multirow[t]{3}{*}{ Number of living child } & None & 2729 & 28.9 \\
\hline & $1-4$ & 4051 & 42.9 \\
\hline & 5 and plus & 2670 & 28.3 \\
\hline \multirow[t]{2}{*}{ Husband occupation } & No & 3798 & 40.2 \\
\hline & Yes & 5652 & 59.8 \\
\hline \multirow[t]{2}{*}{ Age of at first birth } & $\leq 17$ year & 2926 & 31.0 \\
\hline & $>17$ year & 6524 & 69.0 \\
\hline \multirow[t]{3}{*}{ Wealth index } & Poor & 5200 & 55.0 \\
\hline & Middle & 1798 & 19.0 \\
\hline & Riche & 2452 & 25.9 \\
\hline \multirow[t]{3}{*}{ Education of husband } & No education & 6612 & 70.0 \\
\hline & Primary & 2119 & 22.4 \\
\hline & Secondary and plus & 719 & 7.6 \\
\hline \multirow[t]{3}{*}{ Births in last three years } & No birth & 5480 & 58.0 \\
\hline & One birth & 3381 & 35.8 \\
\hline & Two and plus & 589 & 6.2 \\
\hline \multirow[t]{4}{*}{ Access to mass media } & No & 7975 & 84.4 \\
\hline & Yes & 1475 & 15.6 \\
\hline & Tigray & 1195 & 12.6 \\
\hline & Afar & 816 & 8.6 \\
\hline \multirow[t]{5}{*}{ Region } & Amhara & 1381 & 14.6 \\
\hline & Oromia & 1498 & 15.9 \\
\hline & Somali & 914 & 9.7 \\
\hline & Benishangul-Gumuz & 902 & 9.5 \\
\hline & SNNPR & 1495 & 15.8 \\
\hline
\end{tabular}


Table 1 Socio-demographic characteristics of sexual active rural women in Ethiopia (Continued)

\begin{tabular}{llll}
\hline Variables & Categories & Frequency & Percentage \\
\hline & Gambela & 643 & 6.8 \\
& Harari & 339 & 3.6 \\
& Dire dawa & 267 & 2.8 \\
\hline
\end{tabular}

in Tigray region (Table 2). However, Women living in Amhara (AOR 1.88; 95\%CI: 1.54, 2.31) and SNNPR $(\mathrm{AOR}=1.45 ; 95 \% \mathrm{CI}: 1.13,1.87)$ were more likely to use modern contraceptive as compared to women living in the Tigray region (Table 2).

\section{Random effect measures of variation}

The results of random effects indicated that there was a statistically significant variation in the use of modern contraceptives across the clusters (Table 3). In other words, the use of modern contraceptives was not similarly distributed across the clusters. The Intra-cluster correlation coefficients (ICC) revealed that $31.64 \%$ of the variation in the use of modern contraceptives could be attributed to community-level factors. After adjusting for individual-level and community-level factors, there is a significant variation in the use of modern contraceptives across communities or clusters. About $86.69 \%$ of modern contraceptive use in clusters was explained in the full model. Moreover, the MOR confirmed that the use of modern contraceptives was attributed to community-level factors. The MOR for modern contraceptive use was 7.06 in the null model; this indicated that there was variation between communities (clustering), since; 7.06 times higher than the reference (MOR = $1)$. The unexplained community variation in the use of modern contraceptives was reduced to MOR of 2.04 when all factors were added to the model. This indicated that when all factors are considered, the effects of clustering are still statistically significant in the full models (Table 3).

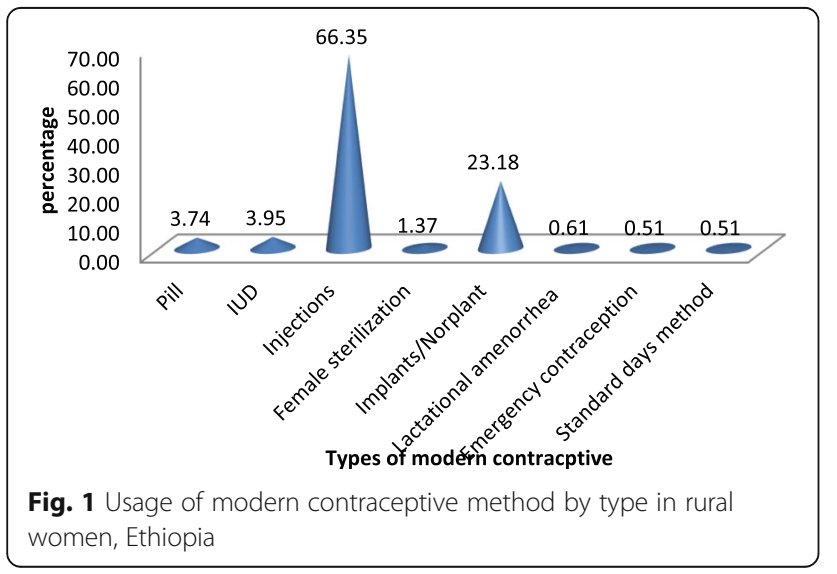

\section{Discussion}

Girls' and women's ability to control their fertility, and to decide if and when to have children and how many children to have, is the bedrock of women's empowerment, gender equality, and progress for all. Therefore, this study was aimed to assess the prevalence of modern contraceptive use and associated predictors among sexually active rural women in Ethiopia.

The result of this study showed that $20.9 \%$ of the respondent used a modern contraceptive method which is lower than that reported from 2016 EDHS 35\% [7]. In urban areas, women may have greater faith in decisionmaking confidence, autonomy, availability of contraceptive methods, and even better living standards than rural women [14]. One of the barriers was the longer distance to health facilities in rural areas, with more job opportunities in urban areas. And also women living in urban areas have good access like family planning to various services [15]. Similarly, this result was lower than Ghana(33.2\%) [16], South Africa (41.8\%) [16], and Kenya(68.9\%) [17]. This might be due to the variations in socio-demographic features and the time gap between the studies.

Among modern contraceptive users, $66.35 \%$ of women use injection, $23.18 \%$ uses the implant, and $10.47 \%$ of women use other modern contraceptive methods. It coincides with studies done in Ethiopia [18, 19]. These findings have demonstrated women's preference for short-acting hormonal contraceptive methods such as injections and tablets. However, in pregnancy prevention, long-acting reversible techniques such as IUDs and implants as well as permanent techniques are considered to be more effective [20].

The results of multilevel logistic regression for random effects indicated that there was a significant variation in the use of modern contraceptive methods across the clusters. In the last full model with both individual and community-level factors accounted for, about $86.69 \%$ of the variation was observed for the use of modern contraceptive methods. It was in agreement with studies in Ethiopia [14, 21], and Nigeria [22].

This study revealed that an increasing educational level of respondents; whose husbands were more likely to use a modern contraceptive method. This result was consistent with previous studies [14, 21-25]. This could be explained by the fact that educated women have better access to health care information, have greater 
Table 2 Multilevel logistic regression output for predictor of modern contraceptive use among sexually active rural women in Ethiopia, 2016 EDHS

\begin{tabular}{|c|c|c|c|c|}
\hline Variables & $\begin{array}{l}\text { Model } 1 \\
\text { AOR }(95 \% \mathrm{Cl})\end{array}$ & $\begin{array}{l}\text { Model } 2 \\
\text { AOR }(95 \% \mathrm{Cl})\end{array}$ & $\begin{array}{l}\text { Model } 3 \\
\text { AOR(95\%Cl) }\end{array}$ & $\begin{array}{l}\text { Model } 4 \\
\text { AOR }(95 \% \mathrm{Cl})\end{array}$ \\
\hline \multicolumn{5}{|l|}{ Individual-level factors } \\
\hline \multicolumn{5}{|l|}{ Education of women } \\
\hline No education & & 1 & & 1 \\
\hline Primary & & 1.03(0.92-1.14) & & $1.31(1.14-1.51)^{\mathrm{a}}$ \\
\hline Secondary and plus & & $0.90(0.76-1.09)$ & & $1.39(1.06-1.81)^{\mathrm{a}}$ \\
\hline \multicolumn{5}{|l|}{ Occupation of respondents } \\
\hline Housewife & & 1 & & 1 \\
\hline Government employed/farmer/private business & & $1.46(1.31-1.62)^{\mathrm{a}}$ & & $1.19(1.05-1.35)^{\mathrm{a}}$ \\
\hline \multicolumn{5}{|l|}{ Marital status } \\
\hline Never married & & 1 & & 1 \\
\hline Married & & $27.82(19.32-40.06)^{\mathrm{a}}$ & & $17.31(10.72-27.94)^{a}$ \\
\hline Others & & $9.54(6.34-14.35)^{\mathrm{a}}$ & & $8.10(5.11-12.82)^{a}$ \\
\hline \multicolumn{5}{|l|}{ Wealth index } \\
\hline Poor & & 1 & & 1 \\
\hline Middle & & $2.24(1.97-2.55)^{\mathrm{a}}$ & & $2.05(1.77-2.38)^{a}$ \\
\hline Riche & & $2.55(2.27-2.87)^{\mathrm{a}}$ & & $2.26(1.96-2.60)^{a}$ \\
\hline \multicolumn{5}{|l|}{ Age of respondents } \\
\hline 10-19 & & 1 & & 1 \\
\hline 20-29 & & $5.03(4.18-6.06)^{\mathrm{a}}$ & & $1.14(0.89-1.46)$ \\
\hline $30-39$ & & $5.11(4.23-6.18)^{a}$ & & $0.80(0.60-1.06)$ \\
\hline $40-49$ & & $3.17(2.57-3.91)^{\mathrm{a}}$ & & $0.40(0.29-0.56)^{\mathrm{a}}$ \\
\hline \multicolumn{5}{|l|}{ Religion } \\
\hline Orthodox & & 1 & & 1 \\
\hline Muslim & & $0.29(0.26-0.33)^{a}$ & & $0.29(0.25-0.33)^{\mathrm{a}}$ \\
\hline Others & & $0.75(0.66-0.85)^{a}$ & & $0.67(0.58-0.77)^{a}$ \\
\hline \multicolumn{5}{|l|}{ Ever had a terminated pregnancy } \\
\hline No & & 1 & & 1 \\
\hline Yes & & $1.15(0.96-1.38)$ & & $0.75(0.61-0.91)$ \\
\hline \multicolumn{5}{|l|}{ Number of living child } \\
\hline None & & 1 & & 1 \\
\hline $1-4$ & & $6.36(5.38-7.53)^{a}$ & & $2.70(2.07-3.53)^{a}$ \\
\hline 5 and plus & & $4.22(3.52-5.05)^{\mathrm{a}}$ & & $2.49(1.81-3.43)^{\mathrm{a}}$ \\
\hline \multicolumn{5}{|l|}{ Education of husbands } \\
\hline No education & & 1 & & 1 \\
\hline Primary & & $3.72(3.32-4.16)^{a}$ & & $1.45(1.27-1.67)^{\mathrm{a}}$ \\
\hline Secondary and plus & & $3.18(2.69-3.77)^{\mathrm{a}}$ & & $1.02(0.82-1.27)^{\mathrm{a}}$ \\
\hline \multicolumn{5}{|l|}{ Husbands occupation } \\
\hline No & & 1 & & 1 \\
\hline Yes & & $6.75(5.85-7.79)^{\mathrm{a}}$ & & $2.02(1.63-2.52)^{a}$ \\
\hline \multicolumn{5}{|l|}{ Births in last three years } \\
\hline No birth & & 1 & & 1 \\
\hline One birth & & $1.54(1.40-1.72)^{a}$ & & $0.51(0.44-0.59)^{a}$ \\
\hline
\end{tabular}


Table 2 Multilevel logistic regression output for predictor of modern contraceptive use among sexually active rural women in Ethiopia, 2016 EDHS (Continued)

\begin{tabular}{|c|c|c|c|c|}
\hline Variables & $\begin{array}{l}\text { Model } 1 \\
\text { AOR }(95 \% \mathrm{CI})\end{array}$ & $\begin{array}{l}\text { Model } 2 \\
\text { AOR }(95 \% \mathrm{CI})\end{array}$ & $\begin{array}{l}\text { Model } 3 \\
\text { AOR(95\%Cl) }\end{array}$ & $\begin{array}{l}\text { Model } 4 \\
\text { AOR }(95 \% \mathrm{Cl})\end{array}$ \\
\hline Two and plus & & $0.64(0.50-0.82)^{a}$ & & $0.25(0.19-0.34)^{\mathrm{a}}$ \\
\hline \multicolumn{5}{|c|}{ Age of at first birth (years) } \\
\hline$\leq 17$ & & 1 & & 1 \\
\hline$>17$ & & $0.64(0.57-0.71)^{a}$ & & $1.05(0.93-1.19)^{a}$ \\
\hline \multicolumn{5}{|l|}{ Community-level factors } \\
\hline \multicolumn{5}{|c|}{ Accesses to mass media } \\
\hline No & & & 1 & 1 \\
\hline Yes & & & $1.75(1.55-1.99)^{\mathrm{a}}$ & $1.35(1.16-1.57)^{\mathrm{a}}$ \\
\hline \multicolumn{5}{|l|}{ Region } \\
\hline Tigray & & & 1 & 1 \\
\hline Afar & & & $0.06(0.04,0.10)^{a}$ & $0.12(0.07,0.20)^{\mathrm{a}}$ \\
\hline Amhara & & & $1.77(1.48,2.11)^{\mathrm{a}}$ & $1.88(1.54,2.31)^{\mathrm{a}}$ \\
\hline Oromia & & & $0.86(0.71,1.03)$ & $0.93(0.73,1.18)$ \\
\hline Somali & & & $0.02(0.01,0.04)^{\mathrm{a}}$ & $0.04(0.02,0.10)^{a}$ \\
\hline Benishangul-Gumuz & & & $0.80(0.65,0.99)^{a}$ & $0.83(0.64,1.07)$ \\
\hline SNNPR & & & $1.19(1.00,1.43)$ & $1.45(1.13,1.87)^{\mathrm{a}}$ \\
\hline Gambela & & & $0.69(0.54,0.87)^{a}$ & $0.75(0.55,1.02)$ \\
\hline Harari & & & $0.41(0.29,0.58)^{a}$ & $0.43(0.28,0.65)^{a}$ \\
\hline Dire dawa & & & $0.36(0.24,0.54)^{a}$ & $0.58(0.37,0.91)^{a}$ \\
\hline
\end{tabular}

$1=$ reference category of the categorical variable; ${ }^{\text {a }}$ Significant at $5 \%$ level of significance.

autonomy to make decisions, and have a greater ability to use quality health care services. Women between the ages of 25-29 were more likely to use modern methods of contraceptive as compared to older women. This might be since younger women, who are married are more likely to do their first child to become pregnant [26]. Younger women can also have trouble obtaining family planning services because they may not know where contraception could be accessed or cannot afford services [27]. This association is also proofed in other studies across the world [28].
Several living children had shown a significant association with the use of modern contraceptives. The number of living children increased, the odds of using modern contraceptives are also increased. Previous studies also confirmed that a high number of living children were more likely to use modern contraceptives $[14,22$, $24,26,29,30]$. The reason behind this might be due to that women might not want to have contraception before they have 3-4 children, after that, they want no more children and want to opt for family planning services. This finding suggests women will practice contraception when they meet their desired family size.

Table 3 Measure of variation on individual and community level predictors among sexually active rural women in Ethiopia, EDHS2016

\begin{tabular}{lllll}
\hline Measure of variation & Model 1 (Null model) & Model 2 & Model 3 & Model 4 (Full model) \\
\hline Variance (SE) & $4.23(0.03)^{*}$ & $1.52(0.07)^{*}$ & $3.09(0.05)^{*}$ & $0.56(0.07)^{*}$ \\
PCV (\%) & Reference & 64.00 & 27.07 & 86.69 \\
ICC (\%) & 56.25 & 31.64 & 48.39 & 14.61 \\
MOR & 7.06 & 3.23 & 5.30 & 2.04 \\
Model fit statistics & & & \\
$\quad$ DIC (-2log likelihood) & 8951.65 & 7162.19 & 8362.95 & 6987.24 \\
AIC & 8955.65 & 7212.19 & 8384.95 & 7057.24 \\
BIC & 8969.96 & 7389.48 & 8463.64 & 7305.44 \\
\hline
\end{tabular}

*reference $P$-value $<0.0001$ 
The wealth index was an important predictor of modern contraceptive use. Rich women were more likely to use modern contraceptives than poor women. Previous studies also showed that women in higher socioeconomic families; more likely to use modern contraceptives $[14,22,24,26,29,31]$. Women from wealthy households are more vulnerable to the media and more likely to use modern contraceptives [32]. This is mainly because rich people have access to more things, are better educated, and the capacity to make their own decisions.

Women's employment status has also been associated with the use of modern contraceptives. Working women were more likely to use modern contraceptives than women who were housewives. It was consistent with previous studies [14, 22, 25, 31, 33, 34]. Women who have been working in different occupations are more likely than housewives to exchange knowledge and experience with their colleagues about modern contraception. It was also found that the level of media exposure had a positive association with modern contraceptive use. Women exposed to the media were more likely to use the modern method of contraception than women who were not exposed to the media. The finding is in line with $[14,21,24,29,31]$. This is because mass media exposure could be an important means of improving awareness and motivating women to practice some sort of modern contraceptives. Women, who had given birth to a child in the last 3 years were less likely to use modern contraceptive than those women who had not given birth. This result is in agreement with [14].

The result of this study indicated that religion was strongly associated with modern contraceptive use. Orthodox Christian women were more likely to use modern contraceptives than Muslims and others (Catholic, Protestant, and Traditional). This finding is in line with $[21,26,31,35]$. This might be since the strong belief in the Muslim community in a holly book that considers family planning to be prohibited [26]. The attribute of this result needs further investigation. Never married women had lower odds of using modern contraceptives than those married and others (windowed and divorced). This result is in agreement with previous findings $[25,28,34]$. This is due to rural unmarried women might not practice sexual intercourse before marred. Besides, women whose husbands had working with government-employed/farmer/private businesses were more likely to use modern contraceptives than those who had not worked. The finding is in line with [14].

Furthermore, the use of modern contraceptives has often varied across regions. Women living in Afar, Somali, Harari, Dire Dawa region had lower use of modern contraceptive methods as compared to the Tigray region (as a reference region). This finding proofed studies in
Ethiopia [14] and Malawi [27]. The potential explanation for this regional disparity is that there are variations between regions; in the implementation of family planning services. The non-accessibility of contraceptive methods leads to the highest under-five mortality in Ethiopia [34, 35]. This implies accessibility of contraceptive methods to use will reduce the mortality of children and further health complexity among mothers.

\section{Conclusion}

The prevalence of modern contraceptive use in rural Ethiopia was $20 \%$, which was very low. Injection (66.35\%) was the most common type of modern contraceptive used. Educated women; educated husband, employed women, employed husband, married women, Orthodox Christian women, and at least one living child were positively associated with modern contraceptive use among individual-level factors. Access to media exposure, and regions were significantly associated with community-level factors with modern contraceptive use. Therefore, the government and other stakeholders shall provide educational opportunities; creating awareness about using modern contraceptives, and providing valuable counseling services. Those might increase modern contraceptive methods utilization.

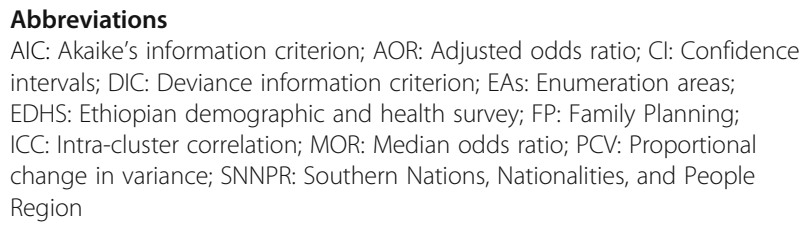

We would like to thank the Ministry of Health and Central Statistical Agency of the Government of Ethiopia, for making the data freely available for research purposes

\section{Authors' contributions}

SMF conceived the original idea of the study, design the study, analyzed the data, and drafted the manuscript. SGG involved with the conception of the study, statistical analysis, interpretation, and revision of the manuscript. Both authors read and approved the final manuscript.

\section{Funding}

None.

\section{Availability of data and materials}

The survey datasets used in this study was based on a publicly available dataset that is freely available online with no participant's identity from http://www.dhsprogram.com/data/available-datasets.cfm. Approval was sought from MEASURE DHS/ICF International and permission was granted for this use.

\section{Declarations}

Ethics approval and consent to participate

This study is a secondary data analysis of the EDHS, which is publicly available, approval was sought from MEASURE DHS/ICF International and permission was granted for this use. The original DHS data were collected in conformity with international and national ethical guidelines. Ethical clearance was provided by the Ethiopian Public Health Institute (EPHI) 
(formerly the Ethiopian Health and Nutrition Research Institute (EHNRI) Review Board, the National Research Ethics Review Committee (NRERC) at the Ministry of Science and Technology, the Institutional Review Board of ICF International, and the United States Centers for Disease Control and Prevention (CDC). Written consent was obtained from mothers/caregivers and data were recorded anonymously at the time of data collection during the EDHS 2016.

\section{Consent for publication}

Not applicable.

\section{Competing interests}

The authors declare that no competing interests exist.

Received: 29 July 2020 Accepted: 24 May 2021

Published online: 04 June 2021

\section{References}

1. Prospects:, U.N.W.P. The 2017 Revision, Key Findings and Advance Tables: Department of Economic and Social Affairs, Population Division; 2017: Working Paper; 2017. p. No. ESA/P/WP/248

2. Bureau., P.R., "2017 World Population Data Sheet." Available at: http://www. prb.org/pdf17/2017_World_Population.pdf. 2017.

3. UNICEF, The State of the World's Children 2017. Available at: https://www. unicef.org/sowc/. 2017

4. United Nations, D.o.E.a.S.A., Population Division, World Population Prospects 2019: Highlights (ST/ESA/SER.A/423). Available from:https: //population.un. org/wpp/Publications/Files/WPP2019_Highlights.pdf. 2019.

5. Ahmed S, et al. Trends in contraceptive prevalence rates in sub-Saharan Africa since the 2012 London summit on family planning: results from repeated cross-sectional surveys. Lancet Glob Health. 2019;7(7):e904-11.

6. Pison G, The population of the world. Population \&. Sociétés. 2019;2019(8): $1-8$.

7. Ethiopian Demographic and Health Survey (2011). Central Statistics Agency, Addis Ababa, Ethiopia. Available from: https://dhsprogram.com/pubs/pdf/ FR328/FR328.pdf. 2016

8. Ezra M. Demographic responses to environmental stress in the drought-and famine-prone areas of northern Ethiopia. Int J Popul Geogr. 2001;7(4):25979 .

9. Zhang H. Fertility Intentions and Subsequent Behaviors Among Thai Married Women: The Kanchanaburi Demographic Surveillance System, 2000-2004; 2007.

10. Merlo J, et al. A brief conceptual tutorial of multilevel analysis in social epidemiology: using measures of clustering in multilevel logistic regression to investigate contextual phenomena. J Epidemiol Community Health. 2006; 60(4):290-7.

11. Austin PC, et al. Measures of clustering and heterogeneity in multilevel $P$ oisson regression analyses of rates/count data. Stat Med. 2018;37(4):572-89.

12. Halonen Jl, et al. Quantifying neighbourhood socioeconomic effects in clustering of behaviour-related risk factors: a multilevel analysis. PLoS One. 2012;7(3):e32937.

13. Zuur AF, et al. Zero-truncated and zero-inflated models for count data, in Mixed effects models and extensions in ecology with R: Springer; 2009. p. 261-93.

14. Abate MG, Tareke AA. Individual and community level associates of contraceptive use in Ethiopia: a multilevel mixed effects analysis. Arch Public Health. 2019;77(1):46.

15. Dodoo FNA, Tempenis M. Gender, power, and reproduction: rural-urban differences in the relationship between fertility goals and contraceptive use in Kenya. Rural Sociol. 2002;67(1):46-70.

16. Chersich $\mathrm{M}$, et al. Contraception coverage and methods used among women in South Africa: a national household survey. S Afr Med J. 2017; 107(4):307-14.

17. Asaolu I, et al. Healthcare system indicators associated with modern contraceptive use in Ghana, Kenya, and Nigeria: evidence from the performance monitoring and accountability 2020 data. Reprod Health. 2019; 16(1):152.

18. Tekelab T, Melka AS, Wirtu D. Predictors of modern contraceptive methods use among married women of reproductive age groups in Western Ethiopia: a community based cross-sectional study. BMC Womens Health. 2015;15(1):52.
19. Belda SS, et al. Modern contraceptive utilization and associated factors among married pastoralist women in bale eco-region, bale zone, south East Ethiopia. BMC Health Serv Res. 2017;17(1):194.

20. Health, W.H.O.R. Family planning: a global handbook for providers: evidence-based guidance developed through worldwide collaboration: Johns Hopkins Ccp-Info; 2007.

21. Agbadi, P., et al., A multilevel analysis of predictors of modern contraceptive use among reproductive age women in Sierra Leone: insight from demographic and Health surveys. 2019.

22. Idris H. Factors Affecting the Use of Contraceptive in Indonesia: Analysis from the National Socioeconomic Survey (Susenas). KEMAS: Jurnal Kesehatan Masyarakat 2019;15(1):117-23.

23. Debebe, Z., E. Tachbele, and N. Dereje, Predictors of modern contraceptive utilization among married reproductive age women in Misha district, Southern Ethiopia: A community based cross sectional study

24. Rutaremwa G, et al. Predictors of modern contraceptive use during the postpartum period among women in Uganda: a population-based cross sectional study. BMC Public Health. 2015;15(1):262.

25. Mandiwa $C$, et al. Factors associated with contraceptive use among young women in Malawi: analysis of the 2015-16 Malawi demographic and health survey data. Contracept Reprod Med. 2018;3(1):12.

26. Musa A, et al. Factor associated with experience of modern contraceptive use before pregnancy among women who gave birth in Kersa HDSS Ethiopia. BMC Public Health. 2016;16(1):614.

27. Mandiwa $\mathrm{C}$, et al. Factors associated with contraceptive use among young women in Malawi: analysis of the 2015-16 Malawi demographic and health survey data. Contracept Reprod Med. 2018;3(1):1-8.

28. Taye EB, Mekonen DG, Debele TZ. Prevalence of post partum modern family planning utilization and associated factors among postpartum mothers in Debre Tabor town, north West Ethiopia, 2018. BMC Res Notes. 2019;12(1): 430.

29. Nsanya MK, et al. Modern contraceptive use among sexually active women aged 15-19 years in North-Western Tanzania: results from the adolescent 360 (A360) baseline survey. BMJ Open. 2019;9(8):e030485.

30. Devita VD, Rosliza A, Suriani I. Prevalence of modern contraceptive use among reproductive women with hypertension and diabetes in a government hospital in BATAM, Indonesia and its socio-demographic determinants. Int J Public Health Clin Sci. 2018;5(4):297-78.

31. Aragaw KA. Application of logistic regression in determining the factors influencing the use of modern contraceptive among married women in Ethiopia. Am J Theor Appl Stat. 2015;4(3):156-62.

32. Ahmed $\mathrm{S}$, et al. Economic status, education and empowerment: implications for maternal health service utilization in developing countries PLoS One. 2010:5(6):e11190.

33. Martin $\mathrm{V}$, et al. Prevalence and determinants of modern contraceptive methods use among women of reproductive age (15-49 years) in rural setting: a case of Kishapu District, Shinyanga Region. Adv Sex Med. 2019; 9(4):53-66.

34. Seyife A, et al. Utilization of modern contraceptives and predictors among women in Shimelba refugee camp, Northern Ethiopia. PLoS One. 2019;14(3): e0212262.

35. Walelign D, et al. Modern contraceptive use among orthodox Christian and Muslim women of reproductive age group in Bahir Dar City, north West Ethiopia: comparative cross sectional study. Open J Epidemiol. 2014;4(04): 235.

\section{Publisher's Note}

Springer Nature remains neutral with regard to jurisdictional claims in published maps and institutional affiliations. 